\title{
Isolation and identification of peste des petits ruminants virus from goats in Egyptian governorates
}

\author{
Sahar Ahmed1(D), Wafaa Abd El Wahab Hosny², Mervat Mahmoud² and Mohamed Abd El-Fatah Mahmoud ${ }^{3}$ (D)
}

1. Department of Cell Biology, Genetic Engineering and Biotechnology Research Dvision, National Research Centre, 12622 Dokki, Giza, Egypt; 2. ELISA Unit and Virus Strains Bank, Animal Health Research Institute, Agriculture Research Centre, Dokki, Giza, Egypt; 3. Department of Parasitology and Animal Diseases, Veterinary Research Division, National Research Centre. Dokki Giza, Egypt.

Corresponding author: Sahar Ahmed, e-mail: selnahta@yahoo.com

Co-authors: WAH: wafaaabdelwahab@gmail.com, MM: mervat_maa@yahoo.com, MAM: m_elfatatri@yahoo.com Received: 27-11-2020, Accepted: 01-03-2021, Published online: 17-04-2021

doi: www.doi.org/10.14202/vetworld.2021.926-932 How to cite this article: Ahmed S, Hosny WA, Mahmoud M, Mahmoud MA (2021) Isolation and identification of peste des petits ruminants virus from goats in Egyptian governorates, Veterinary World, 14(4): 926-932.

\begin{abstract}
Background and Aim: The peste des petits ruminants (PPR) is a highly contagious disease of small ruminants which negatively affects animal production and the socioeconomic status of farmers. Peste des petits ruminants virus (PPRV) encodes eight proteins, with the viral fusion protein $(\mathrm{F})$ playing a role in virus virulence and stimulating an effective protective immune response. This study aimed to isolate and complete the identification of PPRV circulating in goats in different Egyptian governorates and perform molecular characterization of the PPRVF gene.

Materials and Methods: Samples were collected from unvaccinated animals with clinical signs suggestive of PPR. A total of 256 sera were tested for the detection of PPRV antibodies using a competitive enzyme-linked immunosorbent assay (c-ELISA) kit, while 214 samples of blood buffy coat preparation, animal swabs (nasal, ocular, and saliva), and fecal and tissue samples were tested for the detection of the PPRV antigen using an antigen-capture ELISA kit. Molecular diagnosis, gene cloning, blast analysis, and phylogenetic analysis were performed for the molecular characterization of PPRV.

Results: The seroprevalence results of PPRV antibodies in the tested sera showed a total of $67.9 \%$ positive samples. The rates of PPR antigen recorded by the antigen-capture ELISA in the swabs (nasal and ocular) and tissue samples were $44.3 \%$, $46.8 \%$, and $43.5 \%$, respectively, with saliva swabs having the highest rate of PPRV positivity (76.4\%) and fecal samples having the lowest $(33.3 \%)$. Molecular characterization of the PPRV Vero cell culture revealed that the circulating PPRV strain belongs to the IV lineage. Blast analysis of the PPRV F gene showed 96.7\% identity with the PPRV strain Egypt-2014 fusion protein (F) gene, KT006589.1, differing by 43 single-nucleotide polymorphisms.

Conclusion: The results of this study indicate that the emerging PPRV belongs to the IV lineage among small ruminant animals. The findings also indicate the need for an innovative strategy to control and eliminate this disease based on a regularly administered and effective vaccine, a test to distinguish between infected and vaccinated animals, and the need for further study on the protein structure and $P P R V F$ gene expression, which should help us to understand the molecular evolution of the virus and control and eliminate PPR disease.
\end{abstract}

Keywords: molecular virology, peste des petits ruminants, serological study, small ruminants.

\section{Introduction}

Peste des petits ruminants (PPR) is a widespread animal disease that mainly afflicts goats and sheep. Peste des petits ruminants virus (PPRV) was first reported in Africa on the Ivory Coast; it is a highly contagious disease of small ruminants that have significant economic impacts. These impacts are due to the high morbidity and mortality rates, in the ranges of $10-90 \%$ and $50-90 \%$, respectively. The virus belongs to the genus Morbillivirus, which is a single-stranded RNA virus of the family Paramyxoviridae [1]. The most common form

Copyright: Ahmed, et al. Open Access. This article is distributed under the terms of the Creative Commons Attribution 4.0 International License (http://creativecommons.org/licenses/ by/4.0/), which permits unrestricted use, distribution, and reproduction in any medium, provided you give appropriate credit to the original author(s) and the source, provide a link to the Creative Commons license, and indicate if changes were made. The Creative Commons Public Domain Dedication waiver (http:// creativecommons.org/publicdomain/zero/1.0/) applies to the data made available in this article, unless otherwise stated. of PPR is the acute form, which is characterized by depression, high fever, anorexia, nasal, and ocular discharge, followed by mouth erosive lesions, pneumonia, and severe diarrhea [2].

The viral genome is a linear, non-segmented, negative-sense single-stranded RNA that is about 15,948 nucleotides in length [3]. It encodes eight proteins, six of which are structural: Fusion (F), nucleocapsid $(\mathrm{N})$, phosphoprotein $(\mathrm{P})$, large $(\mathrm{L})$, hemagglutinin $(\mathrm{H})$, and matrix $(\mathrm{M})$ proteins [3]. The virus fusion protein (F gene) enables PPRV to penetrate the cell membrane and enter the cytoplasm by affecting the fusion of the virus and host cell membranes. This phenomenon is also responsible for virus spread from cell to cell without the formation of free viral particles. The fusion protein is reported to be critical for inducing an effective protective humoral immune response [4]. The virus circulating in Africa, the Middle East, and Central to Southeast Asia presents four genetically distinct lineages, 
three of which (I, II, and III) were first described in Africa, including Guinea, Ivory Coast, Senegal, Mali, Burkina Faso, Ghana, Nigeria, Uganda, and Tanzania, and the fourth one (IV) in Asia [1]. However, the Asian lineage was recently found to have become established in some countries of North Africa and Europe, indicating the continuing spread of the virus [5].

It is assumed that the trade in live animals to Egypt from Ethiopia and Sudan has a role in the spread of this infection into North and East Africa [6]. This is supported by the close relationship between the PPRV IV lineage in Egypt and North Africa and the PPRV lineage initially identified in Sudan [7].

The importance of molecularly characterizing the PPRV F gene is related to its role in determining virulence in infected animals [4]. Considering the socioeconomic impact of PPR disease, this study aimed to isolate and identify the PPRV circulating in goats in different Egyptian governorates and molecularly characterize the $P P R V F$ gene.

\section{Materials and Methods}

\section{Ethical approval}

The experiments were carried out in accordance with the guidelines laid down by the National Research Centre, Animal Ethics Committee, and in accordance with local laws and regulations.

\section{Study period and location}

The study was conducted during the winter of 2017-2019 on goats from small unorganized local Egyptian breed farms in different Egyptian governorates (Cairo, Giza, Dakahlia, Beni-Suef, Sharkia, Gharbia, Alexandria, and Qena, as shown in Table-1)

\section{Samples}

Swabs, tissue, and fecal samples

A total of 214 samples of blood buffy coat preparation $(n=80)$, animal swabs (nasal $[n=52]$, ocular $[n=32]$, and saliva $[n=17])$, fecal $(n=9)$ and tissue $(n=24)$ samples were obtained from different animals (Table-1) and tested to detect the PPRV antigen using capture enzyme-linked immunosorbent assay (ELISA) kit following the manufacturer's instructions (ID Vet Screen, France). Tissue samples (from lung,

Table-1: Types of the collected samples in relation to the governorates.

\begin{tabular}{lccccccc}
\hline Governorates & Serum & B.C & N.S Conj. S S.S F.S Tissues \\
\hline Cairo (El Marg) & 30 & 11 & 7 & 7 & 5 & 3 & 4 \\
Giza & 68 & 32 & 5 & 3 & 3 & 2 & 3 \\
Alexandria & 21 & 4 & 4 & - & - & - & - \\
Sharkia & 25 & 2 & 8 & 5 & 3 & - & 3 \\
Gharbia & 24 & 3 & 10 & 4 & 4 & - & 4 \\
Dakahlia & 23 & 22 & 12 & 11 & - & 3 & 5 \\
Beni-Suef & 39 & - & - & - & - & - & - \\
Qena & 26 & 6 & 6 & 2 & 2 & 1 & 5 \\
Total & 256 & 80 & 52 & 32 & 17 & 9 & 24 \\
\hline
\end{tabular}

$\mathrm{BC}=$ Blood buffy coat, N.S=Nasal swab, Conj. $\mathrm{S}=$ Ocular swab, S.S=Saliva swab, F. S=Fecal swab lymph node, liver, and intestine) were taken from dead animals. Tissue and fecal samples were prepared in accordance with the work of Clarke et al. [8].

\section{Serum samples}

A total of 256 whole-blood samples were collected from unvaccinated goats with signs suggestive of clinical PPR, in plain tubes for serum preparation (Table-1). All sera were tested to detect PPRV antibodies using a competitive ELISA kit following the manufacturer's instructions (ID Screen ${ }^{\circledR}$ PPR Competition, ID Vet, Montpellier, France). The optical density (OD) values were converted to PI using the following formula:

Percentage (PI) PI $=100 \times($ OD sample/OD negative control). The cut-off for seropositivity used was $\leq 50$ percent as recommended by the manufacturer (ID Screen ${ }^{\circledR P P R}$ Competition, ID vet, Montpellier, France).

\section{Molecular diagnosis and characterization of PPRV F gene} Extraction of PPRV RNA

Total RNA was extracted from $250 \mu \mathrm{L}$ of blood buffy coat, nasal, ocular, and saliva samples, and PPRV cultures using TRIZOL (Invitrogen, USA), in accordance with the instructions provided by the manufacturer. The RNA pellets were subsequently dried and kept at $-80^{\circ} \mathrm{C}$ until used for molecular study [9].

\section{Reverse transcription-polymerase chain reaction (RT-PCR)}

This assay allows the detection of the four lineages of PPRV. The RNA pellets were resuspended in $25 \mu \mathrm{L}$ of RNase-free water. RT and partial amplification of the PPRV F gene were performed using a single-tube RT-PCR method with the One-step RT-PCR Kit protocol (SuperScript ${ }^{\circledR}$ III Reverse Transcriptase; Invitrogen), following the manufacturer's instructions.

Primers of the PPRV $F$ gene (5' -AGTACAAAAGATTGCTGATCACAGT-3' and 5'- GGGTCTCGAAGGCTAGGCCCGAATA$\left.3^{\prime}\right)$ [10] were used to confirm the diagnosis of the PPR-positive serological samples. The reaction conditions were $50^{\circ} \mathrm{C}$ for $30 \mathrm{~min}$ to prepare the cDNA; initial activation at $94^{\circ} \mathrm{C}$ for $2 \mathrm{~min}$; followed by 35 cycles of denaturation at $94^{\circ} \mathrm{C}$ for $1 \mathrm{~min}$, annealing at $55^{\circ} \mathrm{C}$ for $1 \mathrm{~min}$, and extension at $72^{\circ} \mathrm{C}$ for $1 \mathrm{~min}$; and then final extension at $72^{\circ} \mathrm{C}$ for $7 \mathrm{~min}$. The RT-PCR products were analyzed by electrophoresis on $2 \%$ agarose gel.

\section{Viral isolation}

For virus propagation, the capture ELISApositive samples were confirmed by RT-PCR and inoculated into confluent monolayer Vero cells (green monkey kidney cells) kindly supplied by AHRI, Dokki, Giza, Egypt. Minimal essential media with L-glutamine without sodium bicarbonate and 10\% 
FCS (Sigma-Aldrich) were used for the culturing. The inoculated cultures were examined daily for evidence of a cytopathic effect (CPE). The CPE produced by PPRV was observed within 5 days post-inoculation in the form of cell rounding and aggregation culminating in the formation of syncytia [8]. Three successive blind passages for each negative sample were made to confirm its negativity. The positive tissue culture isolates were confirmed for the PPRV-positive inoculation by partial amplification of the PPRV F gene (RT-PCR). For separation of the virus from the culture, the CPE culture flasks were frozen at $-80^{\circ} \mathrm{C}$ and thawed 3 times, after which the culture medium was centrifuged at $4^{\circ} \mathrm{C}$ for $15 \mathrm{~min}(3000 \mathrm{rpm})$. The supernatant was used for viral genome extraction and molecular characterization of the PPRVF gene [11].

\section{Full-length amplification of F gene by RT-PCR}

Primers for the full-length $P P R V F$ gene (1641 bp) were designed using Primer 3.0 software (Applied Biosystems, USA). The primer sequences of 5'-ATGACACGGGTCGCAATC-3' and $5{ }^{\prime}$-CTACAGTGATCTCACGTACGACTT-3' were used for RT-PCR using a One-step RT-PCR kit (Invitrogen, USA) with a thermal cycling program of $45^{\circ} \mathrm{C}$ for $30 \mathrm{~min}$ to prepare the cDNA; initial activation at $95^{\circ} \mathrm{C}$ for $15 \mathrm{~min}$; followed by 35 cycles of denaturation at $94^{\circ} \mathrm{C}$ for $1 \mathrm{~min}$, annealing at $50^{\circ} \mathrm{C}$ for $1 \mathrm{~min}$, and extension at $72^{\circ} \mathrm{C}$ for $2 \mathrm{~min}$; and then final extension at $72^{\circ} \mathrm{C}$ for $10 \mathrm{~min}$. The RT-PCR products were analyzed by electrophoresis on $2 \%$ agarose gel. The successfully amplified PPRV F gene fragments (1641 bp) were cut from the agarose gel and purified using a purification kit (Invitrogen, USA), following the manufacturer's instructions.

\section{Cloning of the PPRV $\boldsymbol{F}$ gene in T-easy vector}

The purpose of developing the recombinant $P P R V F$ gene was to keep it isolated for molecular characterization of the full-length $P P R V F$ gene and for further studies of its protein expression. The ampicillin resistance and white/blue colony selection method were used to select the vector required for cloning. The T-easy vector (3000 bp; Promega Corporation, France) contained an ampicillin resistance gene and white/blue colony selection lacZ indicator were used to select the positive colonies contain the PPRV F gene (Figure-1).

The purified full-length $P P R V F$ gene (1641 bp) was subjected to cloning into a T-easy vector, following the manufacturer's instructions. Five microliters of the cloning reaction mixture were added to $50 \mu \mathrm{L}$ of Escherichia coli DH5 $\alpha$ competent cells, incubated on ice for $20 \mathrm{~min}$, heat-shocked at $42^{\circ} \mathrm{C}$ for $45 \mathrm{~s}$, and then put on ice for $2 \mathrm{~min}$. Subsequently, $900 \mu \mathrm{L}$ of Luria-Bertani (Thermo Fisher Scientific, USA) was added, followed by incubation for about $1.5 \mathrm{~h}$ at $37^{\circ} \mathrm{C}$. This mixture was distributed in LuriaBertani agar plates containing $0.5 \mathrm{mM}$ isopropyl- $\beta$-D thiogalactopyranoside (Sigma-Aldrich, Germany) and $80 \mu \mathrm{g} / \mathrm{mL}$ X-gal, supplemented with $100 \mu \mathrm{g} /$ $\mathrm{mL}$ ampicillin (Sigma-Aldrich, Germany), and incubated at $37^{\circ} \mathrm{C}$.

The transformed bacterial cells contained T-easy vector inserted by PPRV F gene showed ampicillin resistance. The recombinant colonies were white on indicator plates and were selected for new LB agar plates. The white E. coli colonies confirming the insertion of the $\mathrm{F}$ gene were selected and recultured on LB plates. Purification of the recombinant vector from transformed cells was performed using a plasmid isolation kit and a DNA-spin ${ }^{\mathrm{TM}}$ Plasmid DNA Purification Kit (iNtRON Biotechnology, South Korea), following the manufacturer's instructions.

\section{Molecular characterization of the cloned PPRV F gene}

The restriction enzyme EcoRI was used following the manufacturer's instructions to obtain the inserted PPRV F gene from the purified recombinant vector. After restriction enzyme digestion of the recombinant vector, the product was analyzed by electrophoresis on $2 \%$ agarose gel, and the PPRV F gene gel fragment was cut and purified using a purification kit (Invitrogen, USA), following the manufacturer's instructions. The purified product was used for PCR amplification of the full-length $P P R V F$ gene, as previously described. The products successfully amplified by PCR were sent for sequencing to Anses Lab France, French Agency for Food, Environmental, and Occupational Health and Safety. The obtained sequences were subjected to a Blast analysis using the available data in GenBank (https://blast.ncbi.nlm.nih. gov/Blast.cgi). The sequence results were submitted to GenBank.

\section{Phylogenetic analysis}

A phylogenetic tree was constructed based on the PPRV F gene for isolates of PPRV (MW039251 Egypt NRC) and available accessions in GenBank. The tree was drawn to scale, with branch lengths representing the number of substitutions per site (next

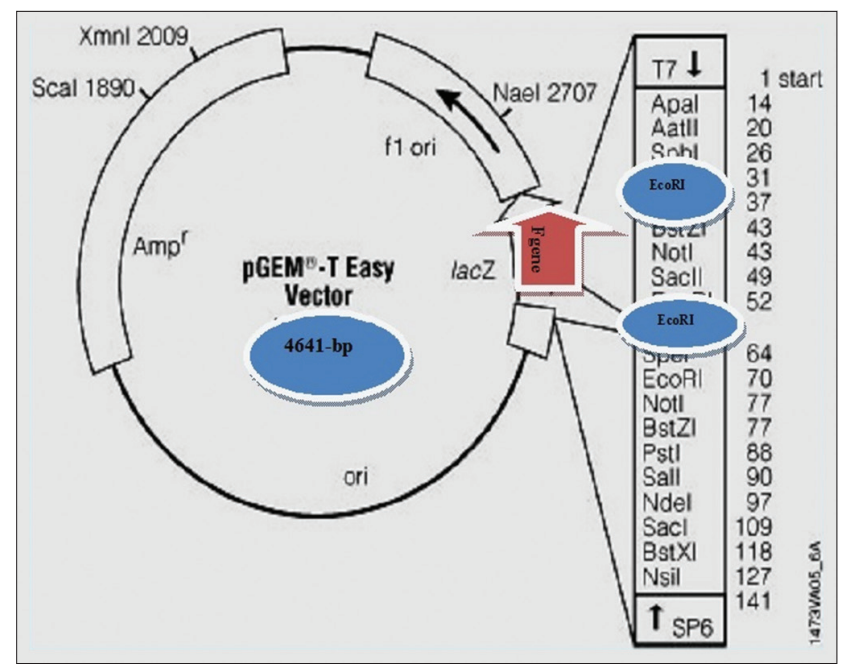

Figure-1: Recombinant of the peste des petits ruminants virus $F$-gene T-easy vector. 
to the branches). The analysis involved 11 nucleotide sequences. The included codon positions were $1^{\text {st }}+2^{\text {nd }}+3^{\text {rd }}+$ Non-coding. All positions containing gaps and missing data were eliminated. There were a total of 760 positions in the final dataset. Evolutionary analyses were conducted using Molecular Evolutionary Genetics Analysis Version 7.0 for Bigger Datasets (https://pubmed.ncbi.nlm.nih.gov/27004904/) [12].

\section{Results and Discussion}

PPR is one of the most economically devastating diseases affecting sheep and goats in developing countries due to its high morbidity and mortality rates, especially in small flocks [13]. Seroprevalence results of PPR antibodies in the tested goats' samples from different governorates are presented in Table-2. The results showed variable numbers of PPRV-positive samples among the different Egyptian governorates. The total positive rate was $67.9 \%$. The highest rate was found in Gharbia governorate $(83.3 \%)$, while the rest of the governorates showed variable rates of PPRV-positive samples. The results of the antibodies in goats' sera against PPRV between Giza and Beni-Suef governorates confirmed previous findings reported by Mahmoud et al. [2] who found that the rates of antibodies in goats sera against PPR were $45.7 \%$ at Giza governorate, and $45 \%$ at BeniSuef governorate.

The results for PPR antigen determined by immunocapture ELISA in the collected samples showed 105 positive samples (Table-3). The swabs (nasal and ocular) and tissue samples showed rates of positivity

Table-2: Seroprevalence of PPRV antibodies detected in goats.

\begin{tabular}{lcccc}
\hline Governorate & $\begin{array}{c}\text { No. of } \\
\text { samples }\end{array}$ & $\begin{array}{c}\text { +ve } \\
\text { samples }\end{array}$ & $\begin{array}{c}\text { +ve } \\
\text { \% }\end{array}$ & $\begin{array}{c}\text { - ve } \\
\text { samples }\end{array}$ \\
\hline Cairo (El Marg) & 30 & 18 & 60 & 12 \\
Giza & 68 & 40 & 58.8 & 28 \\
Alexandria & 21 & 17 & 80.9 & 4 \\
Sharkia & 25 & 16 & 64 & 9 \\
Gharbia & 24 & 20 & 83.3 & 4 \\
Dakahlia & 23 & 18 & 78.2 & 5 \\
Beni-Suef & 39 & 29 & 74.3 & 10 \\
Qena & 26 & 16 & 61.5 & 10 \\
Total & 256 & 174 & & 82 \\
& \multicolumn{5}{c}{$(67.9 \%)$} & & $(32.1 \%)$ \\
\hline
\end{tabular}

for PPR of $44.3 \%, 46.8 \%$, and $43.5 \%$, respectively. The saliva swabs had the highest rate of PPRV positivity (76.4\%), while the fecal samples had the lowest (33.3\%). These results are in agreement with those reported by Nafea and Abdallah [14].

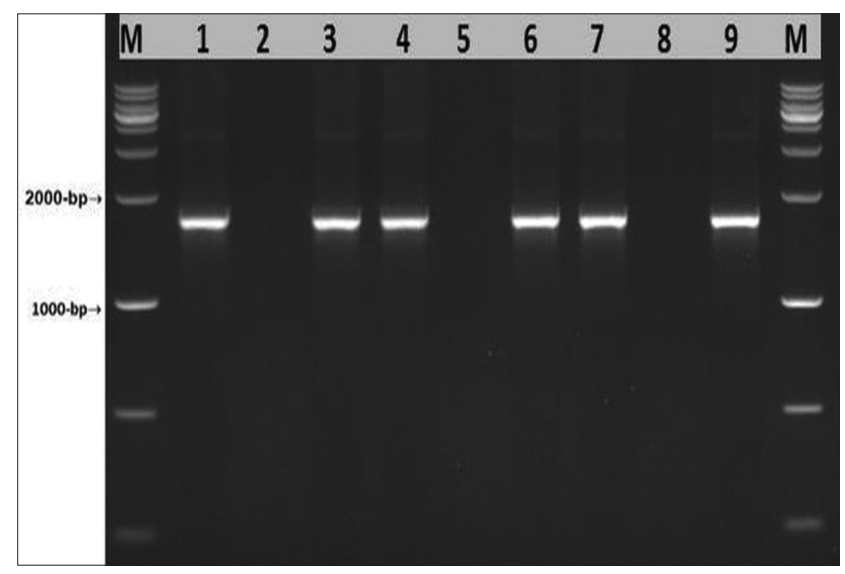

Figure-2: The polymerase chain reaction amplified of the peste des petits ruminants virus $F$ gene full length (1641 bp). M lane M: DNA ladder. Lane: $1,4,5$, and 8 negative samples. Lane: $2,3,6,7$, and 9 positive samples.

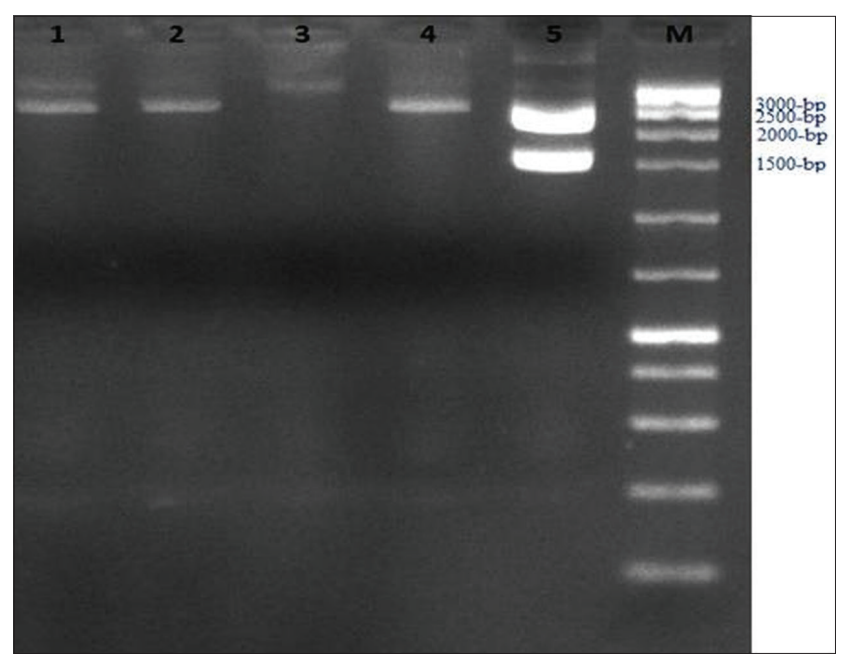

Figure-3: Agarose gel electrophoresis of digested recombinant vector by EcoRI Lane: 1-4 the undigested recombinant vectors. Lane M: DNA ladder $(100,200,300$, $400,500,700,1000,1500,2000,2500,3000,4000$, $5000,6000,8000$, and 10,000 bp). Lane: 5 is digested recombinant vector with two bands at 3000 bp (vector backbone) and $1641 \mathrm{bp}$ (peste des petits ruminants virus $F$ gene fragment).

Table-3: PPRV antigen detected in different goats' samples.

\begin{tabular}{|c|c|c|c|c|c|c|c|c|c|c|c|c|c|c|c|c|c|c|c|c|c|c|c|}
\hline \multirow[t]{2}{*}{ Governorates } & \multicolumn{4}{|c|}{ Buffy coat } & \multicolumn{4}{|c|}{ Nasal swab } & \multicolumn{4}{|c|}{ Ocular swab } & \multicolumn{4}{|c|}{ Saliva swab } & \multicolumn{3}{|c|}{ Fecal swab } & \multicolumn{4}{|c|}{ Tissues } \\
\hline & $\mathbf{N}$ & D & $\mathbf{T}$ & $\%+v e$ & $\mathbf{N}$ & $\mathbf{P}$ & $\mathbf{T}$ & $\%+v e$ & $\mathbf{N}$ & $\mathbf{P}$ & $\mathbf{T}$ & $\%+v e$ & $\mathbf{N}$ & $\mathbf{P}$ & $\mathbf{T}$ & $\%+v e$ & $\mathbf{N} \mathbf{P}$ & & $\%+v e$ & $\mathbf{N}$ & $\mathbf{P}$ & $\mathbf{T}$ & $\%+v e$ \\
\hline & 6 & 5 & 11 & & 3 & 4 & & & & 4 & 7 & & & & & & 1 & 3 & & 3 & 1 & 4 & \\
\hline & 24 & 8 & 32 & & 3 & 2 & & & & 2 & 3 & & & 2 & & & 2 & 2 & & & 2 & 3 & \\
\hline & - & 4 & 4 & & 2 & 2 & & & & - & - & & & - & & & - & - & - & - & - & - & \\
\hline & - & 2 & 2 & & 5 & 3 & 8 & & 3 & 2 & 5 & & & 1 & & & - & - & - & - & 3 & 3 & \\
\hline & - & 3 & 3 & & 7 & 31 & 10 & & 4 & - & 4 & 0 & & 4 & 4 & & - & - & - & 4 & - & 4 & 0 \\
\hline & 7 & 15 & 22 & 68 & 5 & 71 & 12 & & 6 & $\begin{array}{ll}5 & 1\end{array}$ & 11 & & - & - & - & - & 21 & 3 & 33.3 & 3 & 2 & 5 & 40 \\
\hline & 1 & 5 & 6 & & 4 & 2 & 6 & & - & 2 & 2 & & - & 2 & 2 & & $1-$ & 1 & 0 & 4 & 1 & 5 & 20 \\
\hline Total & 38 & $42 \varepsilon$ & 80 & 52.5 & 29 & 235 & 52 & 44.2 & 17 & 153 & 32 & 46.8 & 3 & 131 & 17 & 76.4 & 63 & 9 & 33.3 & 15 & 92 & 24 & 43.5 \\
\hline
\end{tabular}

$\mathrm{N}=$ Negative, $\mathrm{P}=$ Positive, $\mathrm{T}=$ Total, $\%+\mathrm{ve}=$ Percent of positive 
The results suggested that, because there was no history of vaccination, the detected antibodies were related to active infection. In the past few years, several outbreaks of PPR disease have been reported in Egypt $[2,14,15]$. These previous studies focused on animal markets, which play an essential role in disease transmission as there are no restrictions on animal movement during epidemics. The findings of high infection rates in our study confirmed the results in previous studies. Accordingly, the strategy applied to eradicate PPR disease is not effective, so there is a need for an innovative strategy to control and eliminate the disease based on a regular and effective vaccine against the disease among small ruminants, a test to distinguish between infected and vaccinated animals (DIVA), and controls placed on the transport of animals across borders.

The isolation of PPRV through cell culture techniques is considered the gold standard for accurately diagnosing infection, although it is time-consuming [16]. Vero cells are used for the propagation of PPRV as these cells are easily accessible and can easily be maintained and grown for a long time in vitro [17]. The results of the inoculated tissue culture for the samples with positive ELISA results (105)

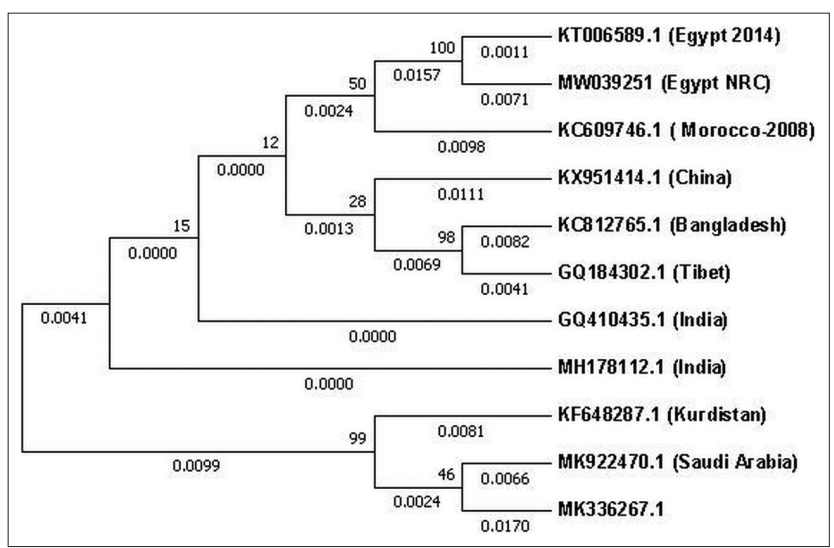

Figure-4: Phylogenetic tree showing the genetic relationships between isolates of peste des petits ruminants virus (MW039251 Egypt NRC) and the available accession numbers from GenBank. The tree was constructed based on peste des petits ruminants virus $F$ gene sequences. The analysis was performed using the MEGA7 software [11] and the maximum likelihood method. on Vero cells yielded 22 viral isolates as follows: Buffy coat $(n=7)$, nasal swabs $(n=4)$, ocular swabs $(n=5)$, saliva swabs $(n=3)$, and tissue samples $(n=3)$. There were fewer yielded isolates than expected (22/105) (Table-4). This could be due to the nature of the virus as it is RNA virus, so it is heat-labile and any leakage in the cold chain in the transportation of samples and the cell culture used [17]. All negative samples were confirmed to be negative by RT-PCR. The positive tissue culture isolates were confirmed by molecular PCR analysis for the PPRVF gene. The products successfully amplified by PCR showed a $480 \mathrm{bp}$ fragment from all 22 isolates.

The full length of the PPRV F gene is reported to be $1641 \mathrm{bp}[14,18]$. Tissue culture isolates confirmed to be positive by partial amplification of the PPRV F gene were used as templates for full-length amplification of the PPRV F gene. Figure- 2 shows the successful amplification of the full-length $P P R V F$ gene (1641 $\mathrm{bp})$. The $P P R V F$ gene cloning was performed to isolate the gene for several analyses. A molecular study of a positive recombinant vector inserted with the $P P R V$ $F$ gene was performed using a restriction enzyme and PCR-based method. The recombinant vector digested by EcoRI was run on an agarose gel to confirm the presence of the vector backbone and the inserted gene. The vector band was identified at $3000 \mathrm{bp}$, while the $P P R V F$ gene band was found at 1641 bp (Figure-3).

The sequence results of the products of the $P P R V$ $F$ gene successfully amplified by PCR were deposited in GenBank with accession numbers MW039251 and MW039252. Blast analysis of the sequence results showed $96.7 \%$ similarity with the PPRV fusion protein gene isolate from Egypt (KT006589.1, 2014) (Figure-4), 96.54\% for one from Izatnagar/India (MH178112.1, 2018), 97\% for one from Ethiopia (KJ867541.1, 2010), and 95.93\% for a PPRV strain from Morocco (KC609746.1, 2013). The phylogenetic tree in Figure-4 shows the genetic relationships among the isolates of PPRV and the available accessions from GenBank. The phylogenetic analysis suggested that the circulating PPRV Egyptian strain belongs to the IV lineage $[19,20]$.

Single-nucleotide polymorphism (SNP) is defined as a substitution of a single nucleotide at a

Table-4: PPR tissue culture for the positive capture ELISA samples and RT-PCR analysis.

\begin{tabular}{|c|c|c|c|c|c|c|c|c|c|c|c|c|c|c|c|c|c|c|}
\hline \multirow[t]{2}{*}{ Governorates } & \multicolumn{3}{|c|}{ Buffy coat } & \multicolumn{3}{|c|}{ Nasal swab } & \multicolumn{3}{|c|}{ Ocular swab } & \multicolumn{3}{|c|}{ Saliva swab } & \multicolumn{3}{|c|}{ Fecal swab } & \multicolumn{3}{|c|}{ Tissues } \\
\hline & $\mathbf{T}$ & CPE & RT-PCR & $\mathbf{T}$ & CPE & RT-PCR & $\mathbf{T}$ & CPE & RT-PCR & $\mathbf{T}$ & CPE & RT-PCR & $\mathbf{T}$ & CPE & RT-PCR & $\mathbf{T}$ & CPE & RT-PCR \\
\hline Cairo (El Marg) & 5 & 2 & 2 & 4 & 2 & 2 & 4 & 1 & 1 & 4 & 1 & 1 & 2 & 0 & 0 & 1 & 1 & 1 \\
\hline Giza & 8 & 1 & 1 & 2 & 0 & 0 & 2 & 1 & 1 & 2 & 1 & 1 & - & - & - & 2 & 1 & 1 \\
\hline Alexandria & 4 & 1 & 1 & 2 & 0 & 0 & 0 & 0 & 0 & - & - & - & - & - & - & - & - & - \\
\hline Sharkia & 2 & 0 & 0 & 3 & 0 & 0 & 2 & 0 & 0 & 1 & 0 & 0 & - & - & - & 3 & 0 & 0 \\
\hline Gharbia & 3 & 0 & 0 & 3 & 0 & 0 & 0 & 0 & 0 & 4 & 0 & 0 & - & - & - & - & - & - \\
\hline Dakahlia & 15 & 2 & 2 & 7 & 1 & 1 & 5 & 2 & 2 & - & - & - & 1 & 0 & 0 & 2 & 1 & 1 \\
\hline Qena & 5 & 1 & 2 & 2 & 1 & 1 & 2 & 1 & 1 & 2 & 1 & 1 & - & - & - & 1 & 0 & 0 \\
\hline Total & 42 & 7 & 7 & 23 & 4 & 4 & 15 & 5 & 5 & 13 & 3 & 3 & 3 & 0 & 0 & 9 & 3 & 1 \\
\hline
\end{tabular}

RT-PCR $=$ Reverse transcription polymerase chain reaction, ELISA=Enzyme-linked immunosorbent assay, CPE $=$ Cytopathic effect, $\mathrm{T}=$ Total 


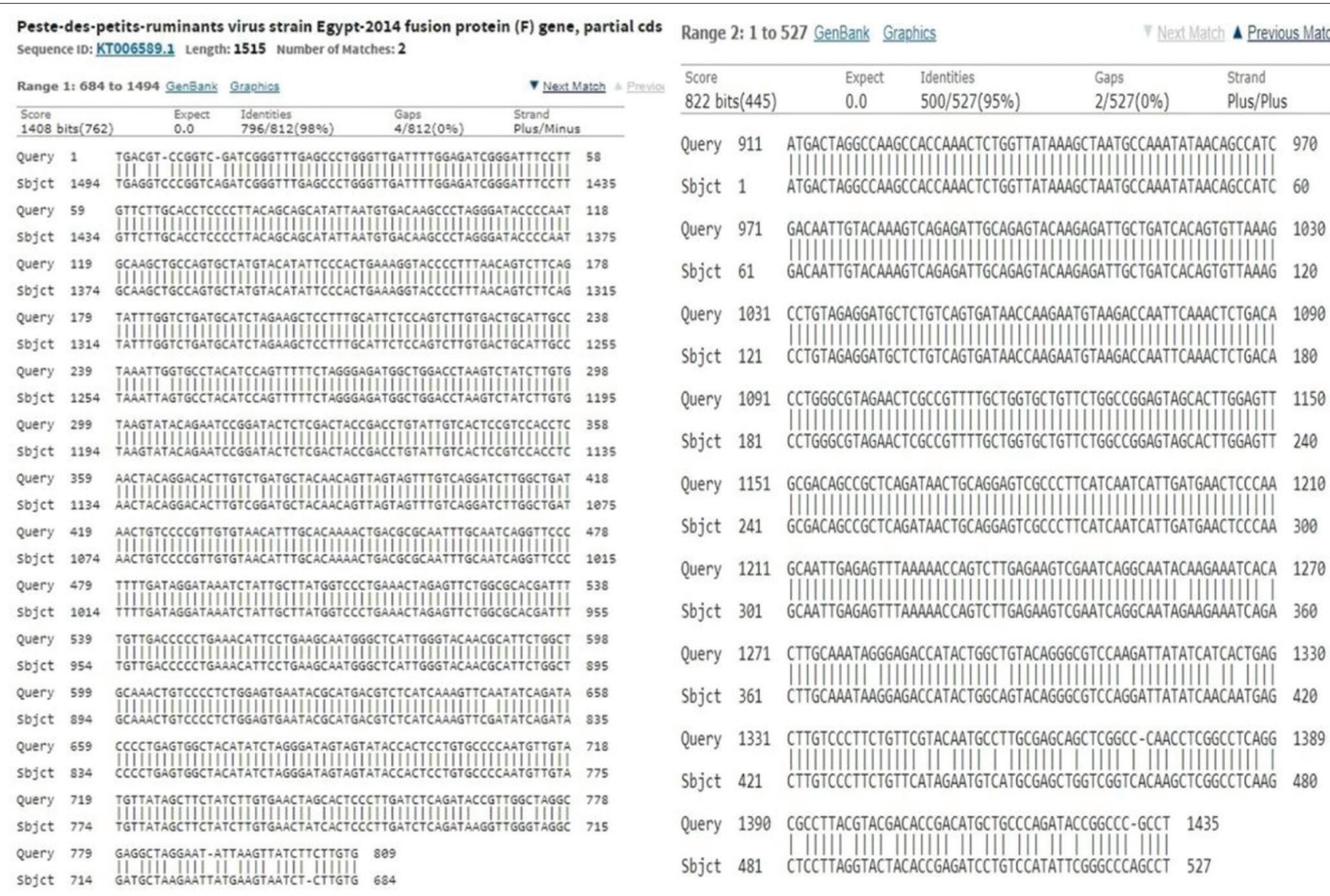

Figure-5: Blast analysis of the peste des petits ruminants virus $F$ gene.

specific position in the genome. SNPs in the coding region are of two types: Synonymous and non-synonymous SNPs. Synonymous SNPs do not affect the protein sequence, while non-synonymous SNPs change the amino acid sequence of the protein and can thus change the gene function [21].

Blast analysis showed that the sequence of the studied PPRV F gene is $96.7 \%$ similar to the PPRV strain Egypt-2014 fusion protein (F) gene (sequence ID: KT006589.1) (Figure-5). They differ in terms of 43 SNPs. The obtained results suggested that this difference in 43 SNPs could play a role in the overall function of the PPRV F gene since the full length of the $P P R V F$ gene encodes a specific protein responsible for virus virulence [4].

\section{Conclusion}

The results of this study indicated that the emerging PPRV belongs to the IV lineage among small ruminant animals, which negatively affects animal production and the socioeconomic status of farmers. The findings also indicated the need for an innovative strategy to control and eliminate the disease based on a regularly administered and effective vaccine, a test to DIVA, and the need for further study on the protein structure and PPRV F gene expression, which will enable us to understand the molecular evolution of the virus and control and eliminate PPR disease.

\section{Authors' Contributions}

SA as the principal author, carried out the molecular laboratory work and wrote the manuscript. WAH and MM carried out the laboratory work related to ELISA and virus isolation. MAM performed the fieldwork, collected the samples, and drafted the manuscript. All authors read and approved the final manuscript.

\section{Acknowledgments}

The authors would like to thank the Science and Technology Development Fund (STDF) for the financial support (Project ID: 18516, Egypt) of the National Challenge Projects grant.

\section{Competing Interests}

The authors declare that they have no competing interests.

\section{Publisher's Note}

Veterinary World remains neutral with regard to jurisdictional claims in published institutional affiliation.

\section{References}

1. Luka, P.D., Erume, J., Mwiine, F.N., Ayebazibwe, C. and Shamaki, D. (2011) Molecular characterization and phylogenetic study of peste des petits ruminants viruses from Northcentral States of Nigeria. BMC Vet. Res., 4: 32.

2. Mahmoud, M.A.E., Elbayoumy, M.K., Sedky, D. and Ahmed, S. (2017) Serological investigation of some 
important RNA viruses affecting sheep and goats in Giza and Beni-Suef governorates in Egypt. Vet. World, 10(10): 1161-1166.

3. Bailey, D., Banyard, A., Dash, P., Ozkul, A. and Barrett, T. (2005) Full genome sequence of peste des petits ruminants virus, a member of the Morbillivirus genus. Virus Res., 110(1-2): 119-124.

4. Berhe, G., Minet, C., Le Goff, C., Barrett, T., Ngangnou, A., Grillet, C., Libeau, G., Fleming, M., Black, D.N. and Diallo, A. (2003) Development of a dual recombinant vaccine to protect small ruminants against peste-des-petits-ruminants virus and capripoxvirus infections. J. Virol., 77(2): 1571-1577.

5. Parida, S., Muniraju, M., Altan, E., Baazizi, R., Raj, G.D. and Mahapatra, M. (2016) Emergence of PPR and its threat to Europe. Small Rumin. Res., 142: 16-21.

6. Hekal, S.H.A., Al-Gaabary, M.H., El-Sayed, M.M., Sobhy, H.M. and Fayed, A.A.A. (2019) Seroprevalence of some infectious transboundary diseases in cattle imported from Sudan to Egypt. J. Adv. Vet. Anim. Res., 6(1): 92-99.

7. Kwiatek, O., Ali, Y.H., Saeed, I.K., Khalafalla, A.I., Mohamed, O.I., Obeida, A.A., Abdelrahman, M.B., Osman, H.M., Taha, K.M., Abbas, Z., El Harrak, M., Lhor, Y., Diallo, A., Lancelot, R., Albina, E. and Libeau, G. (2011) Asian lineage of peste des petits ruminants virus, Africa. Emerg. Infect. Dis., 17(7): 1223-1231.

8. Clarke, B., Mahapatra, M., Friedgut, O., Bumbarov, V. and Parida, S. (2017) Persistence of lineage IV peste-des-petits ruminants virus within Israel since 1993: An evolutionary perspective. PLoS One, 12(5): e0177028.

9. Baazizi, R., Mahapatra, M., Clarke, B.D., Ait-Oudhia, K., Khelef, D. and Parida, S. (2017) Peste des petits ruminants (PPR): A neglected tropical disease in Maghreb region of North Africa and its threat to Europe. PLoS One, 12(4): e0175461.

10. World Organisation for Animal Health. (2019) OIE Terrestrial Manual. Peste des Petits Ruminants. Vol. 3. World Organisation for Animal Health, Paris, France. p1-16.

11. Bodjo, S.C., Lelenta, M., Couacy-Hymann, E. and
Kwiatek, O. (2008) Mapping the peste des petits ruminants virus nucleoprotein: Identification of two domains involved in protein self-association. Virus Res., 131(1): 23-32.

12. Kumar, S., Stecher, G. and Tamura, K. (2016) MEGA7: Molecular evolutionary genetics analysis version 7.0 for bigger datasets. Mol. Biol. Evol., 33(7): 1870-1874.

13. Aitken, I.D. (2007) Diseases of Sheep. $4^{\text {th }}$ ed. Blackwell Science, Hoboken.

14. Nafea, M. and Abdallah, F. (2019) Virological and molecular studies on peste des petits ruminants virus (PPRV) in small ruminants and camel in Egypt between 2017 and 2018. Adv. Anim. Vet. Sci., 7(2s): 12-18.

15. Abd, W., Wahab, E. and Baheeg, E.M., Abd El Raheem Aly, H., Abd El Nabi, S.S. and Hanna, N.M. (2020) Field serological investigation for peste des petits ruminants, foot-and-mouth disease, and bluetongue diseases in illegally introduced animals in Egypt. Vet. World, 13(8): 1661-1666.

16. Hemmatzadeh, F., Boardman, W., Alinejad, A., Hematzade, A. and Moghadam, M.K. (2016) Molecular and serological survey of selected viruses in free-ranging wild ruminants in Iran. PLoS One, 11(12): 1-14.

17. Latif, A. (2018) Comparative analysis of BTS-34 and vero76 cell lines for isolation of peste des petits ruminants (PPR) virus. Pak. Vet. J., 38(3): 237-242.

18. Belsham, G., Anderson, E., Murray, P., Anderson, J. and Barrett, T. (1989) Immune response and protection of cattle and pigs generated by a vaccinia virus recombinant expressing the F protein of rinderpest virus. Vet. Rec., 124(25): 655-658.

19. Muniraju, M., Munir, M. and Parthiban, A.R. (2014) Molecular evolution of peste des petits ruminants virus. Emerg. Infect. Dis., 20(12): 2023-2033.

20. El Ashmawy, W.R., Bazid, A.I., Abdelkader, M., Sakr, M.A., Fayed, A.M. and Fawzy, M. (2018) Molecular epidemiological study on peste des petits ruminants in Egypt 2015. Slov. Vet. Res., 55(4): 205-212.

21. Jia, M., Yang, B., Li, Z., Shen, H., Song, X. and Gu, W. (2014) Computational analysis of functional single nucleotide polymorphisms associated with the CYP11B2 gene. PLoS One, 9(8): e104311.

\section{$* * * * * * * *$}

